\title{
POTENCIAL ANTIMICROBIANO E ANTIBIOFILME IN VITRO DE ESPÉCIES DO GÊNERO EUGENIA, MYRTACEAE, NATIVAS DO SUL DO BRASIL
}

\author{
Carla Kauffmann ${ }^{1}$, Ana Paula Venter Soares ${ }^{2}$, Kelen Arossi ${ }^{3}$, Leandra Andressa Pacheco ${ }^{4}$, \\ Bárbara Buhl ${ }^{5}$, Elisete Maria de Freitas ${ }^{6}$, Lucélia Hoehne ${ }^{7}$, Luís César de Castro ${ }^{8}$, \\ Simone Cristina Baggio Gnoatto ${ }^{9}$ Eduardo Miranda Ethur ${ }^{10}$
}

Resumo: $\mathrm{O}$ controle de infecções bacterianas tem se tornado um problema de saúde pública, despertando o interesse pela pesquisa de substâncias com ação antimicrobiana ou inibidora da formação de biofilme a partir de plantas. Assim, este trabalho objetivou avaliar o potencial antimicrobiano de espécies do gênero Eugenia, nativas do sul do Brasil, contra Staphylococcus aureus e Pseudomonas aeruginosa. Folhas de E. anomala, E. arenosa, E. hiemalis, E. pitanga, E. pyriformis e E. rostrifolia foram submetidas ao processo de maceração com diferentes solventes, resultando nos extratos bruto, hexânico, clorofórmico, acetato de etila e etanólico. Os diferentes extratos foram caracterizados fitoquimicamente através de cromatografia em camada delgada. As atividades antimicrobiana e antibiofilme dos extratos, nas concentrações de 4,0

1 Farmacêutica. Mestre em Ciências Farmacêuticas. Doutora em Ambiente e Desenvolvimento. Professora do Centro de Ciências Biológicas e da Saúde, Univates. E-mail:carlakauffmann@univates.br

2 Farmacêutica. E-mail: anapaula.taj@gmail.br

3 Farmacêutica. E-mail: kelen.arossi@hotmail.com

4 Biomédica. Mestranda no Programa de Pós-Graduação em Biotecnologia, Univates. E-mail: leandrapacheco@universo.univates.br

5 Acadêmica do Curso de Farmácia, Univates. E-mail: barbara.buhl@univates.br

6 Programas de Pós-graduação em Biotecnologia e Ensino, Laboratório de Propagação de Plantas. E-mail: elicauf@univates.br

7 Doutora em Química, Programa de Pós-Graduação em Biotecnologia, UNIVATES, luceliah@ univates.br

8 Farmacêutico. Doutor em Microbiologia Agrícola e do Ambiente. Professor do Centro de Ciências Biológicas e da Saúde, Univates. E-mail: lucamsc@univates.br

9 Farmacêutica. Doutora em Ciências Farmacêuticas. Professora do Curso de Farmácia, UFRGS. E-mail: simone.gnoatto@ufrgs.br

10 Doutor em Química. Professor do Programa de Pós-Graduação em Ambiente e Desenvolvimento (PPGAD), do Programa de Pós-Graduação em Biotecnologia e do Centro de Ciências Exatas e Tecnológicas, Univates. E-mail: eduardome@univates.br 
e $0,4 \mathrm{mg} / \mathrm{mL}$, foram avaliadas em microplacas através da medida de densidade óptica, com auxílio do corante cristal violeta, contra S. aureus (ATCC 25923) e P. aeruginosa (ATCC 27853). Flavonoides, taninos, terpenos e saponinas foram identificados nas amostras. Atividade inibidora sobre o crescimento planctônico de $P$. aeruginosa superior a $90,0 \%$ foi observada para o extrato bruto de $E$. anomala, extrato etanólico de $E$. arenosa e extrato bruto de E. pyriformis, na concentração de $4,0 \mathrm{mg} / \mathrm{mL}$. Ainda, o extrato etanólico de $E$. arenosa, na concentração de $4,0 \mathrm{mg} / \mathrm{mL}$, inibiu em aproximadamente $50,0 \%$ a formação de biofilme de $P$. aeruginosa. Os extratos etanólico e clorofórmico de E. hiemalis e o extrato etanólico de E. pyriformis, na concentração de $4,0 \mathrm{mg} / \mathrm{mL}$, inibiram completamente o crescimento planctônico de $S$. aureus. Os extratos hexânico $4,0 \mathrm{mg} / \mathrm{mL}$, hexânico $0,4 \mathrm{mg} / \mathrm{mL}$ e clorofórmico $4,0 \mathrm{mg} / \mathrm{mL}$ de $E$. hiemalis apresentaram efeito inibidor sobre a formação de biofilme de $S$. aureus superior a $90,0 \%$. Ainda, as espécies nativas do bioma Pampa, E. arenosa, E. anomala e E. pitanga, apresentaram ação inibidora de formação de biofilme na concentração de $0,4 \mathrm{mg} / \mathrm{mL}$, superior a $50,0 \%$ sobre $S$. aureus, contudo sem interferência no crescimento de células planctônicas. Este estudo, além de avaliar pela primeira vez a atividade antimicrobiana e antibiofilme das espécies nativas do gênero Eugenia contra $S$. aureus e $P$. aeruginosa, demonstrou a potencialidade das espécies estudadas como antimicrobianas, destacando-se aquelas originárias do bioma pampa $-E$. anomala, E. arenosa e E. pitanga, como possível fonte para o desenvolvimento de fármacos.

Palavras-chave: Eugenia spp., atividade antimicrobiana, atividade antibiofilme, Pseudomonas aeruginosa, Staphylococcus aureus, bioma Pampa.

\title{
POTENTIAL ANTIMICROBIAL AND ANTIBIOFILM IN VITRO OF SPECIES FROM EUGENIA GENUS, MYRTACEAE, NATIVES FROM SOUTHERN OF BRAZIL
}

\begin{abstract}
The control of bacterial infections has become a public health problem, arousing interest in the research of substances with antibacterial or antibiofilm activities from plants. Thus, this study aims to evaluate the antimicrobial potential of species of the Eugenia spp., native to southern Brazil, against Staphylococcus aureus and Pseudomonas aeruginosa. Leaves from E. anomala, E. arenosa, E. hiemalis, E. pitanga, E. pyriformis and E. rostrifolia were submitted to maceration with different solvents, resulting in crude extracts, hexanic, chloroformic, ethyl acetate and ethanolic. Chemical profiles of the extracts were determined by thin layer chromatography. Antimicrobial and antibiofilm activity of extracts, at concentrations of 4.0 and $0.4 \mathrm{mg} / \mathrm{mL}$, against $S$. aureus (ATCC 25923) and P. aeruginosa (ATCC 27853), employing $\mathrm{OD}_{600}$ absorbance and crystal violet assay in 96 -well microtiter plates. Flavonoids, tannins, terpenes and saponins, were identified in the samples. Inhibitory activity on the planktonic bacterial growth of $P$. aeruginosa more than $90.0 \%$ was observed for the crude extract of $E$. anomala, ethanolic extract of E. arenosa and crude extract of E. pyriformis, at concentration of $4.0 \mathrm{mg} / \mathrm{mL}$. The ethanolic extract of $E$. arenosa, at concentration of $4.0 \mathrm{mg} / \mathrm{mL}$, inhibited approximately $50.0 \%$ the biofilm formation of $P$. aeruginosa. Ethanolic and chloroformic extracts of $E$. hiemalis and ethanolic extract of $E$. pyriformis, at concentration of $4.0 \mathrm{mg} / \mathrm{mL}$, completely inhibited the planktonic bacterial growth of $S$. aureus. Hexanic extract at $4.0 \mathrm{mg} / \mathrm{mL}$, hexanic extract at $0.4 \mathrm{mg} / \mathrm{mL}$ and chloroformic extract at $4.0 \mathrm{mg} / \mathrm{mL}$ of E. hiemalis showed inhibitory effect on biofilm formation of $S$. aureus more than $90.0 \%$. Still, the native species of the Pampa biome, E. arenosa, E. anomala e E. pitanga, showed inhibitory action of biofilm formation on concentration of $0.4 \mathrm{mg} / \mathrm{mL}$, exceeding $50.0 \%$ of $S$. aureus, however without interference on the growth of planktonic cells. Thus, this study describes the first antibacterial and antibiofilm screening of native species of the Eugenia genus against $S$. aureus and $P$. aeruginosa and demonstrates the potential of these species as antimicrobial, especially those originating from the pampa biome - E. anomala, E. arenosa e $E$. pitanga, as a possible source for the development of drugs.
\end{abstract}

Keywords: Eugenia spp., antibacterial activity, antibiofilme activity, Pseudomonas aeruginosa, Staphylococcus aureus, Pampa biome. 


\section{INTRODUÇÃO}

A resistência das bactérias aos antimicrobianos e a capacidade de formação de biofilme são ameaças à saúde pública, uma vez que estes fazem com que o controle de infecções bacterianas torne-se cada vez mais difícil (BLACKLEDGE et al., 2013). Atualmente, apesar da resistência bacteriana não ser um fenômeno novo, observa-se um aumento substancial no número de microrganismos patogênicos que apresentam multirresistência aos agentes farmacológicos, sendo que a Organização Mundial de Saúde (OMS) considera as infecções causadas por estes como uma doença emergente, além de um problema de saúde pública. Ainda, é importante salientar que o tratamento de pacientes infectados com estes patógenos é oneroso, implica em maior tempo de hospitalização, uso de medicamentos de alto custo, podendo resultar em morbimortalidade. Staphylococcus aureus e Pseudomonas aeruginosa estão entre os patógenos comumente relacionados à resistência bacteriana, sendo causas de infecções hospitalares (THEURETZBACHER, 2013).

Estima-se que $80 \%$ das infecções microbianas em humanos sejam causadas por bactérias produtoras de biofilme, sendo este um fator que favorece a virulência destas, assim como dificulta seu tratamento. Bactérias associadas com biofilme são até 1000 vezes mais resistentes a antibioticoterapia em comparação com seus homólogos planctônicos, além de serem inacessíveis ao sistema imune do hospedeiro, favorecendo o surgimento de infecções crônicas apesar do uso terapia medicamentosa agressiva. Ainda, biofilmes podem se formar na superfície de dispositivos médicos, gerando uma fonte contínua de infecção que muitas vezes exige a remoção do mesmo. Staphylococcus spp., Pseudomonas aeruginosa, Klebsiella pneumoniae, Serratia marcescens e Enterobacter cloacae, entre outras espécies, são clinicamente relevantes por formarem biofilme e colonizarem dispositivos médicos, causarem infecções crônicas ou apresentarem resistência a antimicrobianos de amplo espectro, como os carbapenemas (BLACKLEDGE et al., 2013; TRENTIN et al., 2013).

A presença de Staphylococcus sp. é comum também em animais, sendo que infecções causadas por $S$. aureus atingem aves, suínos, ovinos e bovinos. Infecções causadas por este microrganismo apresentam impacto econômico, destacando-se os casos de mastite em ruminantes, onde a formação de biofilme é um fator que dificulta o tratamento (PETON; LE LOIR, 2014). Ainda, a presença de microrganismos, destacandose, entre outros, $S$. aureus como patógeno de origem alimentar e $P$. aeruginosa como contaminante, assim como a formação de biofilmes, também gera impacto econômico na indústria alimentícia, principalmente na de processamento de produtos cárneos e lácteos, uma vez que estes infectam alimentos e superfícies de processamento dos mesmos, os quais precisam ser desinfetados de forma eficiente a fim de evitar problemas sanitários (SREY et al., 2013; BRIDIER et al., 2015).

Taraszkiewicz et al. (2013) destacam a importância da etnofarmacologia como ponto de partida para busca de antimicrobianos, tendo em vista o uso de numerosas plantas na medicina popular contra várias doenças. Além disso, os patógenos que 
acometem vegetais são distintos daqueles que causam infecções em humanos, tornando vantajosa a busca de compostos derivados de plantas com potencial farmacológico. Outro fator que favorece a pesquisa a partir de plantas são as características estruturais de seus metabólitos secundários, os quais apresentam baixo peso molecular, como alcaloides, terpenoides, flavonoides, cumarinas, glicosídeos e polifenóis, além de apresentarem mecanismos de ação variados (VILLA; CAPPITELLI, 2013).

Desta forma, a busca por substâncias com ação antimicrobiana ou inibidora da formação de biofilme a partir de plantas é uma opção atrativa como fonte para o desenvolvimento de novas alternativas terapêuticas. O gênero Eugenia, pertencente à família Myrtaceae, é constituído por mais de 1.000 espécies, das quais aproximadamente 350 são encontradas no Brasil, comumente na Floresta Atlântica (FARIA JUNIOR, 2010; SOUZA; LORENZI, 2012). Entre as espécies pertencentes ao gênero destacamse, por seu uso popular, como antimicrobianas, Eugenia uniflora (CORRÊA, 1984; HOLETZ et al., 2002; SOUZA et al., 2004), Eugenia obtusifolia (BUSSMANN et al., 2010) e Eugenia punicifolia (OLIVEIRA et al., 2005).

Estudos realizados com Eugenia brasiliensis (MAGINA et al., 2012), Eugenia calycina (FERREIRA et al., 2014; SOUSA et al., 2015), Eugenia mansoni (BARNECHE et al., 2011), Eugenia uniflora (HOLETZ et al., 2002; SOUZA et al., 2004; OGUNWANDE et al., 2005) e Eugenia uruguayensis (BARNECHE et al., 2011), comprovaram a atividade antimicrobiana de espécies do gênero. Contudo, outras espécies nativas da região sul da América do Sul, como Eugenia anomala D.Legrand, Eugenia arenosa Mattos, Eugenia hiemalis Cambess., Eugenia pitanga (O. Berg) Nied, Eugenia pyriformis Cambess. e Eugenia rostrifolia D.Legrand, apresentam escassos estudos ou não foram avaliadas quanto a suas atividades biológicas ou perfil fitoquímico, constituindo-se em promissoras fontes de pesquisa. Assim, este trabalho objetiva avaliar o potencial antimicrobiano e antibiofilme de espécies do gênero Eugenia, nativas do sul da América do Sul, contra Staphylococcus aureus e Pseudomonas aeruginosa.

\section{MATERIAL E MÉTODOS}

\subsection{Material vegetal}

O material vegetal, constituído de folhas das espécies E. anomala, E. arenosa, E. hiemalis, E. pitanga, E. pyriformis e Eugenia rostrifolia, foi coletado em diferentes municípios do Rio Grande do Sul, abrangendo dois biomas distintos - Mata Atlântica e Pampa (QUADRO 1). A identificação das espécies foi realizada pela Professora Dra. Elisete Maria de Freitas, botânica da Universidade do Vale do Taquari, Univates. Exsicata de cada espécie foi depositada no Herbário do Vale do Taquari (HVAT), do Museu de Ciências Naturais da Univates (QUADRO 1). 
Quadro 1. Espécies do gênero Eugenia, Myrtaceae, nativas do sul do Brasil, utilizadas no estudo

\begin{tabular}{|l|c|l|l|l|}
\hline Espécie & Nome popular & Bioma & $\begin{array}{l}\text { Local de co- } \\
\text { leta }\end{array}$ & Exsicata \\
\hline $\begin{array}{l}\text { E. anomala D.Le- } \\
\text { grand }\end{array}$ & -------- & Pampa & Alegrete & HVAT 4058 \\
\hline E. arenosa Mattos & ------- & Pampa & Alegrete & HVAT 4173 \\
\hline $\begin{array}{l}\text { E. hiemalis Cambess. } \\
\text { ou guamirim-burro }\end{array}$ & $\begin{array}{l}\text { aperta-cu, guamirim } \\
\text { tica }\end{array}$ & Mata Atlân- & Roca Sales & HVAT 4648 \\
\hline $\begin{array}{l}\text { E. pitanga } \text { (O.Berg) } \\
\text { Nied. }\end{array}$ & pitanga-do-campo & Pampa & Alegrete & HVAT 4052 \\
\hline $\begin{array}{l}\text { E. pyriformis } \text { Cam- } \\
\text { bess. }\end{array}$ & uvaia & $\begin{array}{l}\text { Mata Atlân- } \\
\text { tica }\end{array}$ & $\begin{array}{l}\text { Cruzeiro do } \\
\text { Sul }\end{array}$ & HVAT 2245 \\
\hline $\begin{array}{l}\text { E. rostrifolia } \text { D.Le- } \\
\text { grand }\end{array}$ & $\begin{array}{r}\text { batinga ou batinga- } \\
\text {-vermelha }\end{array}$ & $\begin{array}{l}\text { Mata Atlân- } \\
\text { tica }\end{array}$ & Imigrante & HVAT 1790 \\
\hline
\end{tabular}

a SOBRAL et al., 2013.

b FLORA DIGITAL, 2010.

\subsection{Preparação dos extratos}

As folhas das espécies analisadas foram secas em temperatura ambiente e depois trituradas em liquidificador industrial. Amostras das espécies foram submetidas ao processo de maceração com etanol 90\%, na proporção 1:10 - droga:solvente (m/v), por 7 dias, obtendo-se, desta forma, o extrato bruto.

A fim de obter frações enriquecidas de metabólitos secundários foram preparados extratos com solventes de polaridade crescente - hexano, clorofórmio, acetato de etila e etanol. Amostras de cada espécie foram maceradas nos solventes citados, de forma sequencial, por 7 dias em cada solvente, na proporção 1:10 de droga:solvente $(\mathrm{m} / \mathrm{v})$. Desta forma, foram obtidos os extratos hexânico, clorofórmico, acetato de etila e etanólico. Após, o material foi filtrado e concentrado em evaporador rotatório, em temperatura inferior a $50{ }^{\circ} \mathrm{C}$.

\subsection{Análises fitoquímicas}

Os diferentes extratos de cada espécie foram caracterizados, através de cromatografia em camada delgada (CCD), empregando cromatofolhas de alumínio com sílica gel $60 \mathrm{~F}_{254}$ (Merck ${ }^{\bigotimes}$, Germany). A identificação da presença de diferentes classes de metabólitos secundários foi realizada com emprego de sistema eluente e 
reagente de visualização específico, associada à visualização sob luz ultravioleta em 254 nm e 366 nm (QUADRO 2), de acordo com Wagner e Bladt (1996). Ácido ursólico (Sigma-Aldrich Co, USA) foi empregado como padrão cromatográfico.

Quadro 2. Condições cromatográficas de análise dos extratos de espécies do gênero Eugenia, Myrtaceae, nativas do sul do Brasil

\begin{tabular}{|l|l|l|}
\hline $\begin{array}{l}\text { Classe de } \\
\text { metabólito }\end{array}$ & Fase móvel (volume) & Reagente de visualização \\
\hline Alcaloides & $\begin{array}{l}\text { diclorometano:metanol } \\
(95: 5)\end{array}$ & Reagente de Dragendorff \\
\hline Antraquinonas & $\begin{array}{l}\text { acetato de etila:metanol:água } \\
(100: 13.5: 10)\end{array}$ & $\begin{array}{l}\text { Solução etanólica de hidróxido de } \\
\text { potássio 5\% }\end{array}$
\end{tabular}

Observação sob luz ultravioleta em $254 \mathrm{~nm}^{\mathrm{a}}$ e $366 \mathrm{~nm}^{\mathrm{b}}$.

\subsection{Microrganismos e condições de cultura e análise}

$\mathrm{Na}$ avaliação do potencial antimicrobiano e antibiofilme foram empregadas cepas American Type Culture Collection (ATCC) de Staphylococcus aureus (ATCC 25923) e Pseudomonas aeruginosa (ATCC 27853). Na determinação da adesão bacteriana empregou-se microplacas de poliestireno com 96 poços, de fundo chato (Corning Incorporated, USA), ou seja, um modelo de material hidrofóbico.

Os microrganismos foram cultivados em ágar Mueller Hinton, durante a noite, em estufa a $37^{\circ} \mathrm{C}$. Após, suspensão bacteriana foi preparada em solução estéril de salina, correspondente a $3 \times 10^{8} \mathrm{UFC} / \mathrm{mL}$, para utilização nos ensaios. 


\subsection{Ensaio de atividade antibiofilme}

$\mathrm{Na}$ realização dos ensaios para análise da atividade antibiofilme foi empregada metodologia de Trentin et al. (2011). A cada poço da placa de microtitulação foram adicionados $80 \mu \mathrm{L}$ da suspensão bacteriana, $40 \mu \mathrm{L}$ de amostra dos extratos em estudo e $80 \mu \mathrm{L}$ de caldo triptona de soja (TSB) (Oxoid Ltd., England). As amostras foram testadas nas concentrações de $0,4 \mathrm{mg} / \mathrm{mL}$ e $4,0 \mathrm{mg} / \mathrm{mL}$.

As placas foram incubadas em estufa, a $37^{\circ} \mathrm{C}$, por 24 horas. Após, o teor dos poços foi removido e estes foram lavados três vezes com solução estéril de salina. A placa foi colocada em estufa a $60^{\circ} \mathrm{C}$, por uma hora, a fim de fixar o biofilme formado. O biofilme formado foi corado com solução de cristal violeta $0,4 \%$, à temperatura ambiente, por 15 minutos. Após, foram adicionados $200 \mu \mathrm{L}$ de etanol (Synth ${ }^{\oplus}$, Brasil) para solubilizar o corante e a absorbância foi medida a $570 \mathrm{~nm}$, em espectrofotômetro (SpectraMax i3x Multimode Microplate Reader, Molecular Devices, USA).

A absorbância do controle de crescimento, no qual a amostra foi substituída por $40 \mu \mathrm{L}$ de água estéril, foi considerada como $100 \%$ de formação de biofilme, sendo a partir desta calculada a inibição de formação de biofilme pelas amostras analisadas. Valores superiores a 100\% representam uma estimulação da formação de biofilme em comparação ao controle.

\subsection{Ensaio de crescimento bacteriano}

O crescimento de bactérias planctônicas foi determinado pela diferença entre a absorbância em $600 \mathrm{~nm}$ medida ao final, tempo 24 horas, e ao início do período de incubação, tempo 0 hora, em espectrofotômetro (SpectraMax i3x Multimode Microplate Reader, Molecular Devices, USA).

No controle do crescimento bacteriano foram adicionados $40 \mu \mathrm{L}$ de água estéril em substituição a amostra, sendo este considerado como $100 \%$ de crescimento bacteriano planctônico. Valores superiores a $100 \%$ representaram estimulação do crescimento bacteriano em relação ao controle. Gentamicina 0,16 mg/mL (Sigma-Aldrich Co., USA) e vancomicina $0,16 \mathrm{mg} / \mathrm{mL}$ (Sigma-Aldrich Co., USA) foram empregados como controles de inibição do crescimento bacteriano.

\subsection{Análise estatística}

As amostras foram analisadas em quadriplicata, sendo os experimentos realizados em triplicata. Os resultados foram expressos como percentagem média \pm desviopadrão. A significância das diferenças entre as amostras foi calculada por teste $t$ de Student, empregando o software BioEstat 5.0, considerando-se valores de $p \leq 0,05$ como diferença significativa. 


\section{RESULTADOS E DISCUSSÃO}

\subsection{Perfil fitoquímico de espécies do gênero Eugenia, nativas do sul do Brasil}

A presença de alcaloides, a partir da análise cromatográfica, não foi observada em nenhuma das espécies analisadas. Enquanto que a presença de compostos fenólicos foi observada em todas as espécies analisadas, sendo encontrados tanto em frações apolares quanto em mais polares, como o extrato bruto, o que pode indicar a presença de agliconas e formas glicosídicas destes compostos. Taninos foram observados em todas as espécies, assim como flavonoides, sendo que este último grupo não foi identificado apenas na espécie $E$. rostrifolia. Ainda, observou-se a presença de antraquinonas em $E$. biemalis (QUADRO 3). A presença de taninos foi descrita em E. grandis (NONAKA et al., 1987) e E. uniflora (LEE et al., 1997). Flavonoides foram descritos como constituintes em diversas espécies do gênero, como E. uniflora (HARON et al., 1992) E. jambolana (MAHMOUD et al., 2001) e E. brasiliensis (MAGINA et al., 2012).

Quadro 3. Análise fitoquímica de extratos e frações de espécies do gênero Eugenia, Myrtaceae, nativas do sul do Brasil

\begin{tabular}{|l|c|c|c|c|c|c|c|}
\hline Espécie/Extrato & Alcaloides & Antraquinonas & Cumarinas & Flavonoides & Saponinas & Terpenos & Taninos \\
\hline Eugenia anomala & & & & & & & \\
\hline extrato bruto & ----- & ----- & ----- & + & + & + & + \\
\hline extrato hexânico & ----- & ---- & ----- & + & ---- & + & ----- \\
\hline extrato clorofórmico & ----- & ----- & ----- & + & ---- & + & ----- \\
\hline $\begin{array}{l}\text { extrato acetato de } \\
\text { etila }\end{array}$ & ----- & ----- & ----- & + & ---- & + & ----- \\
\hline extrato etanólico & ----- & ----- & ----- & + & ---- & ----- & + \\
\hline Eugenia arenosa & & & & & & & \\
\hline extrato bruto & ----- & ----- & ----- & + & + & + & + \\
\hline extrato hexânico & ------ & ----- & ----- & ----- & ----- & ----- & ----- \\
\hline extrato clorofórmico & ------ & ----- & ----- & ---- & ---- & + & ----- \\
\hline $\begin{array}{l}\text { extrato acetato de } \\
\text { etila }\end{array}$ & ----- & ---- & ---- & + & - & + & ----- \\
\hline extrato etanólico & ------ & ----- & ----- & + & + & + & + \\
\hline Eugenia biemalis & & & & & & & \\
\hline extrato bruto & ----- & + & ----- & + & + & + & + \\
\hline extrato hexânico & ----- & ----- & ----- & ----- & ----- & ----- & ----- \\
\hline extrato clorofórmico & ----- & ----- & ----- & ----- & ----- & + & ----- \\
\hline $\begin{array}{l}\text { extrato acetato de } \\
\text { etila }\end{array}$ & ----- & ----- & ----- & + & ----- & ----- & + \\
\hline extrato etanólico & ----- & + & ----- & + & + & + & + \\
\hline
\end{tabular}




\begin{tabular}{|c|c|c|c|c|c|c|c|}
\hline Espécie/Extrato & Alcaloides & Antraquinonas & Cumarinas & Flavonoides & Saponinas & Terpenos & Taninos \\
\hline \multicolumn{8}{|l|}{ Eugenia pitanga } \\
\hline extrato bruto & ----- & ----- & ----- & + & + & + & + \\
\hline extrato hexânico & ----- & ----- & ----- & ----- & ----- & ----- & ----- \\
\hline extrato clorofórmico & ----- & ----- & ----- & + & ----- & + & ----- \\
\hline $\begin{array}{l}\text { extrato acetato de } \\
\text { etila }\end{array}$ & ----- & ----- & ----- & + & ----- & + & + \\
\hline extrato etanólico & ----- & ----- & ----- & + & + & + & + \\
\hline \multicolumn{8}{|l|}{ Eugenia pyriformis } \\
\hline extrato bruto & ----- & ----- & ----- & ----- & + & + & + \\
\hline extrato hexânico & ----- & ----- & ---- & ----- & ----- & + & ----- \\
\hline extrato clorofórmico & ----- & ----- & ----- & ---- & ----- & + & ----- \\
\hline $\begin{array}{l}\text { extrato acetato de } \\
\text { etila }\end{array}$ & ----- & ----- & ----- & ----- & ----- & + & ----- \\
\hline extrato etanólico & ----- & ----- & ----- & + & ----- & ----- & + \\
\hline \multicolumn{8}{|l|}{ Eugenia rostrifolia } \\
\hline extrato bruto & ----- & ----- & ----- & ----- & + & + & + \\
\hline extrato hexânico & ---- & ----- & ----- & ----- & ----- & ----- & ----- \\
\hline extrato clorofórmico & ---- & ----- & ----- & ---- & ---- & + & ----- \\
\hline $\begin{array}{l}\text { extrato acetato de } \\
\text { etila }\end{array}$ & ----- & ----- & ----- & ----- & ----- & + & ----- \\
\hline extrato etanólico & ----- & ----- & ----- & ----- & + & + & + \\
\hline
\end{tabular}

Legenda: ----- = ausente. $+=$ presente

A presença de terpenos foi verificada em todas as espécies analisadas (QUADRO 3). $\mathrm{Na}$ análise desse grupo de metabólitos empregou-se como padrão cromatográfico ácido ursólico, aglicona triterpênica, identificado como constituinte presente em E. brasiliensis (FRIGHETTO et al., 2005). A presença desta substância pode ser verificada, através da análise cromatográfica, em $E$. anomala, $E$. arenosa, E. hiemalis, $E$. pitanga e $E$. rostrifolia, o que pode ser um indicativo da presença de saponinas contendo núcleo ursólico nestas espécies.

Em todas as espécies de Eugenia analisadas foi observada a presença de saponinas (QUADRO 3). A presença de derivados triterpênicos foi observada em várias espécies do gênero, como em E. fructicosa, E. jambolana e E. wallichii (CHANDLER; HOOPER, 1979), E. brasiliensis (MAGINA et al., 2012) e E. moraviana (LUNARDI et al., 2001).

\subsection{Análise da atividade antimicrobiana e antibiofilme}

Os extratos hexânico e clorofórmico de E. hiemalis e extrato etanólico de $E$. pyriformis, na concentração de $4,0 \mathrm{mg} / \mathrm{mL}$, inibiram completamente o crescimento 
planctônico de S. aureus. Este resultado também foi observado para o extrato hexânico de E. hiemalis, na concentração de $0,4 \mathrm{mg} / \mathrm{mL}$. As frações apolares de E. hiemalis, ainda, apresentaram efeito superior a $90,0 \%$ em relação a inibição da formação de biofilme, verificando-se crescimento séssil de 6,02\% $\pm 0,89,7,74 \% \pm 0,77$ e $6,56 \% \pm$ 0,89 , respectivamente para os extratos hexânico $4,0 \mathrm{mg} / \mathrm{mL}$, hexânico $0,4 \mathrm{mg} / \mathrm{mL}$ e clorofórmico $4,0 \mathrm{mg} / \mathrm{mL}$ (Tabela 1 ).

Tabela 1. Atividade antimicrobiana de extratos e frações de espécies do gênero Eugenia, Myrtaceae, nativas do sul do Brasil, contra S. aureus ATCC 25923

\begin{tabular}{|c|c|c|c|c|c|c|c|c|}
\hline & \multicolumn{4}{|c|}{ Crescimento bacteriano (\%) } & \multicolumn{4}{|c|}{ Formação de biofilme (\%) } \\
\hline & \multicolumn{2}{|c|}{$4,0 \mathrm{mg} / \mathrm{mL}$} & \multicolumn{2}{|c|}{$0,4 \mathrm{mg} / \mathrm{mL}$} & \multicolumn{2}{|c|}{$4,0 \mathrm{mg} / \mathrm{mL}$} & \multicolumn{2}{|c|}{$0,4 \mathrm{mg} / \mathrm{mL}$} \\
\hline \multicolumn{9}{|l|}{ Eugenia anomala } \\
\hline extrato bruto & $0,00^{*}$ & & 135,71 & $\pm 24,75$ & 21,14 & $\pm 2,59^{*}$ & 21,48 & $\pm 0,17^{*}$ \\
\hline extrato hexânico & 21,10 & $\pm 2,03^{*}$ & 155,15 & $\pm 14,36^{*}$ & 25,18 & $\pm 3,46^{*}$ & 28,91 & $\pm 1,39^{*}$ \\
\hline extrato clorofórmico & 100,21 & $\pm 20,65$ & 102,51 & \pm 7.87 & 27,80 & $\pm 4,01^{*}$ & 34,08 & $\pm 1,21^{*}$ \\
\hline extrato acetato de etila & 32,13 & $\pm 2,49^{*}$ & 151,62 & $\pm 30,06$ & 13,27 & $\pm 1,28^{*}$ & 29,64 & $\pm 1,61^{*}$ \\
\hline extrato etanólico & 18,82 & $\pm 2,21^{*}$ & 164,71 & $\pm 50,93$ & 5,65 & $\pm 0,96^{*}$ & 26,68 & $\pm 1,78^{*}$ \\
\hline \multicolumn{9}{|l|}{ Eugenia arenosa } \\
\hline extrato bruto & 107,26 & $\pm 6,75$ & 110,90 & $\pm 15,76$ & 16,46 & $\pm 2,02^{*}$ & 31,37 & $\pm 1,93^{*}$ \\
\hline extrato hexânico & 109,85 & $\pm 13,61$ & 106,90 & $\pm 14,79$ & 7,23 & $\pm 1,04^{*}$ & 15,88 & $\pm 1,00^{*}$ \\
\hline extrato clorofórmico & 85,57 & $\pm 13,38$ & 112,63 & $\pm 11,58$ & 5,22 & $\pm 0,43^{*}$ & 5,29 & $\pm 0,90^{*}$ \\
\hline extrato acetato de etila & 51,47 & $\pm 5,56^{*}$ & 108,54 & $\pm 16,26$ & 8,49 & $\pm 1,27^{*}$ & 8,71 & $\pm 0,25^{*}$ \\
\hline extrato etanólico & 35,65 & $\pm 4,99^{*}$ & 103,84 & $\pm 12,20$ & 8,89 & $\pm 0,36^{*}$ & 10,86 & $\pm 0,83^{*}$ \\
\hline \multicolumn{9}{|l|}{ Eugenia hiemalis } \\
\hline extrato bruto & 62,08 & $\pm 7,94^{*}$ & 1,67 & $\pm 0,46^{*}$ & 20,22 & $\pm 1,45^{*}$ & 4,32 & $\pm 1,05^{*}$ \\
\hline extrato hexânico & $0,00^{*}$ & & $0,00^{*}$ & & 6,02 & $\pm 0,89^{*}$ & 7,74 & $\pm 0,77^{*}$ \\
\hline extrato clorofórmico & $0,00^{*}$ & & 12,89 & $\pm 0,62^{*}$ & 6,56 & $\pm 0,89^{*}$ & 16,89 & $\pm 0,63^{*}$ \\
\hline extrato acetato de etila & 22,29 & $\pm 1,35^{*}$ & 90,77 & $\pm 8,82$ & 7,99 & $\pm 0,59^{*}$ & 37,74 & $\pm 2,21^{*}$ \\
\hline extrato etanólico & 39,69 & $\pm 1,68^{*}$ & 80,16 & $\pm 12,23$ & 24,25 & $\pm 0,92^{*}$ & 35,40 & $\pm 3,81^{*}$ \\
\hline \multicolumn{9}{|l|}{ Eugenia pitanga } \\
\hline extrato bruto & 91,21 & $\pm 18,84$ & 95,19 & $\pm 5,36$ & 29,52 & $\pm 3,80^{*}$ & 28,32 & $\pm 0,93^{*}$ \\
\hline extrato hexânico & 72,14 & $\pm 6,01^{*}$ & 87,64 & $\pm 18,77$ & 31,15 & $\pm 1,04^{*}$ & 20,10 & $\pm 1,05^{*}$ \\
\hline extrato clorofórmico & 77,87 & $\pm 6,31$ & 96,22 & $\pm 3,84$ & 20,12 & $\pm 0,94^{*}$ & 40,11 & $\pm 2,29^{*}$ \\
\hline extrato acetato de etila & 49,80 & $\pm 6,23^{*}$ & 87,83 & $\pm 10,20$ & 62,39 & $\pm 3,04^{*}$ & 46,99 & $\pm 2,75^{*}$ \\
\hline extrato etanólico & 47,82 & $\pm 6,77^{*}$ & 73,74 & $\pm 11,52$ & 25,35 & $\pm 1,51^{*}$ & 16,46 & $\pm 1,62^{*}$ \\
\hline \multicolumn{9}{|l|}{ Eugenia pyriformis } \\
\hline extrato bruto & 17,03 & $\pm 1,85^{*}$ & 151,42 & $\pm 38,39$ & 30,50 & $\pm 2,75^{*}$ & 31,52 & $\pm 3,08^{*}$ \\
\hline extrato hexânico & 73,49 & $\pm 10,45^{*}$ & 122,50 & $\pm 3,87^{*}$ & 29,13 & $\pm 2,30^{*}$ & 40,84 & $\pm 1,68^{*}$ \\
\hline extrato clorofórmico & 39,20 & $\pm 2,73^{*}$ & 64,54 & $\pm 1,03^{*}$ & 23,13 & $\pm 2,68^{*}$ & 114,68 & $\pm 37,27$ \\
\hline extrato acetato de etila & 120,93 & $\pm 30,17$ & 117,33 & $\pm 22,17$ & 78,70 & $\pm 19,87$ & 40,67 & $\pm 4,38^{*}$ \\
\hline
\end{tabular}




\begin{tabular}{l|c|l|r|l|r|l|r|r}
\hline & \multicolumn{3}{|c|}{ Crescimento bacteriano (\%) } & \multicolumn{3}{c}{ Formação de biofilme (\%) } \\
\hline & $4,0 \mathrm{mg} / \mathrm{mL}$ & \multicolumn{2}{|c|}{$0,4 \mathrm{mg} / \mathrm{mL}$} & \multicolumn{2}{c}{$4,0 \mathrm{mg} / \mathrm{mL}$} & \multicolumn{2}{c}{$0,4 \mathrm{mg} / \mathrm{mL}$} \\
\hline extrato etanólico & $0,00^{*}$ & & 142,63 & $\pm 10,85^{*}$ & 23,83 & $\pm 2,17^{*}$ & 40,78 & $\pm 1,30^{*}$ \\
\hline Eugenia rostrifolia & & & & & & & & \\
\hline extrato bruto & 69,26 & $\pm 6,31^{*}$ & 95,00 & $\pm 11,02$ & 63,40 & $\pm 6,46$ & 84,72 & $\pm 3,68^{*}$ \\
\hline extrato hexânico & 90,31 & $\pm 11,62$ & 93,01 & $\pm 9,27$ & 54,62 & $\pm 2,32^{*}$ & 137,29 & $\pm 16,31$ \\
\hline extrato clorofórmico & 72,72 & $\pm 7,01$ & 91,21 & $\pm 10,82$ & 11,62 & $\pm 1,07^{*}$ & 14,78 & $\pm 1,80^{*}$ \\
\hline extrato acetato de etila & 84,60 & $\pm 7,17$ & 96,34 & $\pm 18,11$ & 92,66 & $\pm 3,76$ & 118,39 & $\pm 25,22$ \\
\hline extrato etanólico & 83,13 & $\pm 8,41$ & 94,20 & $\pm 11,76$ & 26,26 & $\pm 2,31^{*}$ & 67,66 & $\pm 9,00^{*}$ \\
\hline
\end{tabular}

*diferença significativa em relação ao controle de crescimento $(p \leq 0,05)$.

A espécie E. arenosa, nativa do bioma Pampa, apresentou resultados interessantes na concentração de $0,4 \mathrm{mg} / \mathrm{mL}$, na qual não interfere no crescimento planctônico, contudo, os extratos fracionados, hexânico, clorofórmico, acetato de etila e etanólico, inibiram a formação de biofilme em valores superiores a 80,0\% (Tabela 1). Perfil semelhante é observado para as espécies E. anomala e E. pitanga, também nativas do bioma Pampa, em que se verifica a manutenção de um ação inibidora de formação de biofilme na concentração de $0,4 \mathrm{mg} / \mathrm{mL}$, superior a $50,0 \%$, contudo sem interferência no crescimento de células planctônicas (Tabela 1).

O extrato clorofórmico de $E$. rostrifolia também apresentou resultados promissores, em ambas as concentrações testadas, $4,0 \mathrm{mg} / \mathrm{mL}$ e $0,4 \mathrm{mg} / \mathrm{mL}$, inibindo em mais de $80,0 \%$ a formação de biofilme $(11,62 \% \pm 1,07$ e $14,78 \% \pm 1,80$ de crescimento séssil, respectivamente). Contudo, não apresenta efeito inibidor significativo sobre células planctônicas, verificando-se $72,72 \% \pm 7,01$ e $91,21 \% \pm 10,82$ de crescimento com a concentração de $4,0 \mathrm{mg} / \mathrm{mL}$ e $0,4 \mathrm{mg} / \mathrm{mL}$, respectivamente (Tabela 1).

Biofilmes podem ser extintos, basicamente, através de duas vias: pelo uso de substâncias bactericidas ou bacteriostáticas, que levarão a inibição do crescimento bacteriano, ou pelo emprego de compostos capazes de bloquear a adesão bacteriana, os quais são classificados como terapia antivirulência, não resultando em morte bacteriana. Atualmente, o desenvolvimento de compostos que inibem a adesão bacteriana, sem afetar o crescimento bacteriano, tem sido pesquisada, pois estes ao manterem as células em seu estado planctônico favorecem a ação do sistema imune do hospedeiro e dos antibióticos existentes, mantendo a eficácia do arsenal corrente de antimicrobianos (TRENTIN et al., 2013, VILLA; CAPPITELLI, 2013). Desta forma, os resultados observados para os extratos de E. anomala, E. arenosa, E. pitanga e extratos clorofórmicos de E. rostrifolia sobre a formação de biofilme de $S$. aureus são promissores, instigando a continuidade dos estudos em busca do possível mecanismo de ação envolvido.

Extratos de E. anomala, na concentração de $4,0 \mathrm{mg} / \mathrm{mL}$, apresentaram atividade inibidora superior a $80,0 \%$ sobre o crescimento planctônico de $P$. aeruginosa, resultando 
em $0,0 \%, 10,81 \% \pm 0,96$ e $14,72 \% \pm 2,07$ de crescimento bacteriano para os extratos bruto, hexânico e etanólico, respectivamente. $\mathrm{O}$ extrato etanólico de E. arenosa, na concentração de $4,0 \mathrm{mg} / \mathrm{mL}$, resultou em $6,66 \% \pm 1,66$ de crescimento bacteriano, ou seja, em ação antimicrobiana superior a $90,0 \%$ sobre células planctônicas de $P$. aeruginosa. Os extratos bruto e etanólico de E. pyriformis, na concentração de 4,0 mg/ $\mathrm{mL}$, resultaram, respectivamente, em $1,65 \% \pm 0,56$ e $17,44 \% \pm 1,27$ de crescimento bacteriano. Os extratos das espécies analisadas na concentração de $0,4 \mathrm{mg} / \mathrm{mL}$ não apresentaram atividade antimicrobiana expressiva contra $P$. aeruginosa, sendo o resultado mais promissor observado para o extrato bruto de $E$. arenosa, o qual inibiu o crescimento planctônico em 52,88\% (Tabela 2).

Tabela 2. Atividade antimicrobiana de extratos e frações de espécies do gênero Eugenia, Myrtaceae, nativas do sul do Brasil, contra P. aeruginosa ATCC 27853

\begin{tabular}{|c|c|c|c|c|c|c|c|c|}
\hline & \multicolumn{4}{|c|}{ Crescimento bacteriano (\%) } & \multicolumn{4}{|c|}{ Formação de biofilme (\%) } \\
\hline & \multicolumn{2}{|c|}{$4,0 \mathrm{mg} / \mathrm{mL}$} & \multicolumn{2}{|c|}{$0,4 \mathrm{mg} / \mathrm{mL}$} & \multicolumn{2}{|c|}{$4,0 \mathrm{mg} / \mathrm{mL}$} & \multicolumn{2}{|c|}{$0,4 \mathrm{mg} / \mathrm{mL}$} \\
\hline \multicolumn{9}{|l|}{ Eugenia anomala } \\
\hline extrato bruto & $0,00^{*}$ & & 64,15 & $\pm 6,71^{*}$ & 100,70 & $\pm 11,88$ & 130,29 & $\pm 16,19$ \\
\hline extrato hexânico & 10,81 & $\pm 0,96^{*}$ & 52,19 & $\pm 1,30^{*}$ & 51,88 & $\pm 1,81^{*}$ & 119,54 & $\pm 23,85$ \\
\hline extrato clorofórmico & 40,12 & $\pm 5,02^{*}$ & 59,37 & $\pm 5,30^{*}$ & 72,12 & $\pm 5,29$ & 82,57 & $\pm 6,33$ \\
\hline extrato acetato de etila & 23,72 & $\pm 3,67^{*}$ & 77,49 & $\pm 4,89^{*}$ & 114,06 & $\pm 24,32$ & 142,40 & $\pm 21,82$ \\
\hline extrato etanólico & 14,72 & $\pm 2,07^{*}$ & 66,30 & $\pm 7,72$ & 97,74 & $\pm 29,50$ & 147,60 & $\pm 48,93$ \\
\hline \multicolumn{9}{|l|}{ Eugenia arenosa } \\
\hline extrato bruto & 30,66 & $\pm 0,48^{*}$ & 47,12 & $\pm 2,02^{*}$ & 102,55 & $\pm 21,85$ & 106,39 & $\pm 17,13$ \\
\hline extrato hexânico & 55,30 & $\pm 6,56^{*}$ & 110,29 & $\pm 28,32$ & 110,43 & $\pm 10,02$ & 129,86 & $\pm 18,33$ \\
\hline extrato clorofórmico & 59,42 & $\pm 2,63^{*}$ & 109,07 & $\pm 19,26$ & 118,21 & $\pm 24,47$ & 132,14 & $\pm 24,00$ \\
\hline extrato acetato de etila & 41,52 & $\pm 4,30^{*}$ & 106,85 & $\pm 11,44$ & 114,40 & $\pm 4,48^{*}$ & 67,56 & $\pm 5,88$ \\
\hline extrato etanólico & 6,66 & $\pm 1,66^{*}$ & 64,40 & $\pm 3,15^{*}$ & 48,13 & $\pm 3,90^{*}$ & 135,44 & $\pm 14,17^{*}$ \\
\hline \multicolumn{9}{|l|}{ Eugenia biemalis } \\
\hline extrato bruto & 45,32 & $\pm 0,84^{*}$ & 78,98 & $\pm 6,49^{*}$ & 75,75 & $\pm 9,12^{*}$ & 127,21 & $\pm 6,97^{*}$ \\
\hline extrato hexânico & 86,86 & $\pm 13,10$ & 119,36 & $\pm 26,17$ & 60,57 & $\pm 5,68^{*}$ & 78,04 & $\pm 4,21^{*}$ \\
\hline extrato clorofórmico & 69,60 & $\pm 7,10$ & 81,72 & $\pm 2,07^{*}$ & 76,26 & $\pm 12,90$ & 103,51 & $\pm 25,59$ \\
\hline extrato acetato de etila & 74,88 & $\pm 8,00^{*}$ & 103,12 & $\pm 11,21$ & 141,04 & $\pm 15,04^{*}$ & 112,92 & $\pm 2,84^{*}$ \\
\hline extrato etanólico & 26,92 & $\pm 2,32^{*}$ & 64,11 & $\pm 6,70^{*}$ & 83,04 & $\pm 14,48$ & 140,04 & $\pm 20,66$ \\
\hline \multicolumn{9}{|l|}{ Eugenia pitanga } \\
\hline extrato bruto & 49,56 & $\pm 1,21^{*}$ & 71,67 & $\pm 4,44$ & 134,22 & $\pm 17,54$ & 145,97 & $\pm 8,62^{*}$ \\
\hline extrato hexânico & 111,78 & $\pm 25,61$ & 93,34 & $\pm 8,16$ & 135,70 & $\pm 25,82$ & 76,88 & $\pm 8,77^{*}$ \\
\hline extrato clorofórmico & 59,26 & $\pm 11,88^{*}$ & 85,97 & $\pm 12,53$ & 87,35 & $\pm 6,27$ & 81,86 & $\pm 9,91$ \\
\hline extrato acetato de etila & 57,13 & $\pm 5,70^{*}$ & 93,95 & $\pm 13,67$ & 89,63 & $\pm 10,87$ & 108,54 & $\pm 0,84^{*}$ \\
\hline extrato etanólico & 31,02 & $\pm 4,05^{*}$ & 68,12 & $\pm 5,85^{*}$ & 100,97 & $\pm 23,90$ & 131,25 & $\pm 12,48^{*}$ \\
\hline \multicolumn{9}{|l|}{ Eugenia pyriformis } \\
\hline extrato bruto & 1,65 & $\pm 0,56^{*}$ & 68,63 & $\pm 4,53^{*}$ & 115,72 & $\pm 10,27$ & 134,49 & $\pm 35,44$ \\
\hline extrato hexânico & 66,68 & $\pm 6,10^{*}$ & 100,87 & $\pm 18,44$ & 123,41 & $\pm 38,17$ & 105,78 & $\pm 26,20$ \\
\hline
\end{tabular}




\begin{tabular}{l|r|l|r|r|r|l|r|r}
\hline & \multicolumn{3}{|c|}{ Crescimento bacteriano (\%) } & \multicolumn{3}{c}{ Formação de biofilme (\%) } \\
\hline & $4,0 \mathrm{mg} / \mathrm{mL}$ & \multicolumn{2}{|c|}{$0,4 \mathrm{mg} / \mathrm{mL}$} & $4,0 \mathrm{mg} / \mathrm{mL}$ & \multicolumn{2}{c}{$0,4 \mathrm{mg} / \mathrm{mL}$} \\
\hline extrato clorofórmico & 56,16 & $\pm 5,79^{*}$ & 84,11 & $\pm 10,10$ & 77,19 & $\pm 5,22$ & 86,57 & $\pm 4,35$ \\
\hline extrato acetato de etila & 110,91 & $\pm 13,09$ & 125,03 & $\pm 48,02$ & 111,97 & $\pm 29,00$ & 115,38 & $\pm 32,58$ \\
\hline extrato etanólico & 17,44 & $\pm 1,27^{*}$ & 83,16 & $\pm 16,88$ & 98,44 & $\pm 9,51$ & 150,48 & $\pm 39,23$ \\
\hline Eugenia rostrifolia & & & & & & & & \\
\hline extrato bruto & 47,25 & $\pm 2,04^{*}$ & 72,96 & $\pm 8,92^{*}$ & 128,14 & $\pm 37,76$ & 128,14 & $\pm 32,61$ \\
\hline extrato hexânico & 63,63 & $\pm 11,95^{*}$ & 81,49 & $\pm 10,72$ & 90,23 & $\pm 4,02$ & 73,79 & $\pm 6,01$ \\
\hline extrato clorofórmico & 79,53 & $\pm 8,14^{*}$ & 89,77 & $\pm 12,73$ & 165,67 & $\pm 13,63 *$ & 88,13 & $\pm 13,82$ \\
\hline extrato acetato de etila & 76,25 & $\pm 11,46$ & 87,08 & $\pm 14,00$ & 84,43 & $\pm 7,16$ & 92,03 & $\pm 4,95$ \\
\hline extrato etanólico & 49,33 & $\pm 2,13^{*}$ & 76,87 & $\pm 11,25$ & 128,28 & $\pm 43,23$ & 136,09 & $\pm 41,34$ \\
\hline
\end{tabular}

*diferença significativa em relação ao controle de crescimento $(p \leq 0,05)$.

Em relação à inibição da formação de biofilme de $P$. aeruginosa, os extratos das espécies analisadas, em ambas as concentrações $(4,0$ e 0,4 mg/mL), não demonstraram resultados expressivos. O extrato etanólico de E. arenosa, na concentração de 4,0 mg/ $\mathrm{mL}$, possibilitou $48,13 \% \pm 3,90$ de formação de biofilme. Além deste, apenas outras cinco amostras, extrato hexânico de E. anomala $4,0 \mathrm{mg} / \mathrm{mL}(51,88 \% \pm 1,81)$; extratos bruto $4,0 \mathrm{mg} / \mathrm{mL}$, hexânico 4,0 e $0,4 \mathrm{mg} / \mathrm{mL}$ de E. hiemalis $(75,75 \% \pm 9,12,60,57 \%$ $\pm 5,68,78,04 \% \pm 4,21)$; e extrato hexânico $0,4 \mathrm{mg} / \mathrm{mL}$ de $E$. pitanga $(76,88 \% \pm 8,77)$ resultaram em formação parcial de biofilme de $P$. aeruginosa em relação ao controle de crescimento (Tabela 2). Contudo, a grande maioria dos extratos não afetou a formação de biofilme (19/30) ou estimulou o crescimento deste (6/30) nos ensaios com $P$. aeruginosa, contrastando com os resultados obtidos nos ensaios com $S$. aureus, em que apenas o extrato acetato de etila de $E$. rostrifolia, em ambas as concentrações testadas, não interferiu no crescimento do biofilme.

A iminência de cepas multirresistentes e, consequente, ineficácia dos antibióticos existentes, tem motivado a pesquisa por compostos bioativos de origem vegetal, sendo diversos os estudos realizados, predominando os que objetivam a avaliação do potencial antimicrobiano. Espécies do gênero Myrtaceae demonstraram acentuada atividade antimicrobiana contra cepas de S. aureus resistentes (ATCC 700699, ATCC 43300, USA 100), sendo que os extratos acetônicos e clorofórmicos de folhas de Eugenia mansoni apresentaram concentração inibitória mínima (MIC) de 7,8 $\mu \mathrm{g} / \mathrm{mL}$ contra estas cepas, enquanto que extratos acetônicos e clorofórmicos de folhas de Eugenia uruguayensis apresentaram MIC de 31,3 $\mu \mathrm{g} / \mathrm{mL}$ (BARNECHE et al., 2011). Extrato bruto de folhas de Eugenia brasiliensis apresentou atividade contra Escherichia coli, $P$. aeruginosa e $S$. aureus com MIC, respectivamente, de $0,78 \mathrm{mg} / \mathrm{mL}, 0,78 \mathrm{mg} / \mathrm{mL}$ e 6,25 $\mathrm{mg} / \mathrm{mL}$ (MAGINA et al., 2012).

O extrato etanólico, bem como suas frações - hexânica, clorofórmica, acetato de etila e aquosa, de folhas e cascas de Eugenia calycina, espécie nativa do Cerrado brasileiro, rica em compostos oxigenados, como flavonoides glicosilados, taninos e polifenóis, 
foram testados contra vários microrganismos. Os resultados mais promissores foram encontrados para a fração hexânica de folhas, constituída por compostos com número reduzido de oxigênios, tais como ácidos graxos e esteroides, com MIC de 31,2 $\mu \mathrm{g} /$ $\mathrm{mL}$ contra Cryptococcus gatti e Cryptococcus neoformans, e de $62,5 \mu \mathrm{g} / \mathrm{mL}$ contra Cryptococcus sp. (FERREIRA et al., 2014). Enquanto que o óleo essencial de folhas da espécie, constituído principalmente por sesquiterpenos, apresentou efeito contra as bactérias orais Prevotella nigrescens e Porphyromonas gingivalis, com MIC de $100 \mu \mathrm{g} / \mathrm{mL}$ (SOUSA et al., 2015). Ainda, o óleo essencial de folhas de Eugenia uniflora, espécie popular no Brasil por seus frutos e empregada por seus efeitos antidiarreico, diurético, antirreumático e antifebril, apresentou atividade contra B. cereus, S. aureus (ATCC 29213), E. coli e $P$. aeruginosa com MIC, respectivamente, de $39 \mu \mathrm{g} / \mathrm{mL}, 156 \mu \mathrm{g} / \mathrm{mL}$, $625 \mu \mathrm{g} / \mathrm{mL}$ e $625 \mu \mathrm{g} / \mathrm{mL}$ (OGUNWANDE et al., 2005).

A atividade antimicrobiana preferencial em relação a bactérias Gram-positivas, como observada no presente estudo, também foi verificada para outras espécies de plantas, podendo estar relacionada à diferença estrutural existente entre microrganismos Gram-positivos e Gram-negativos. P. aeruginosa, além de apresentar a membrana externa, característica de microrganismos Gram-negativos, difere-se de outras espécies por ter um reduzido número de canais de porina, o que contribui para dificuldade em se obter substâncias com atividade antimicrobiana contra esta bactéria (NIKAIDO, 2001).

Kuźma et al. (2007) avaliaram a atividade antimicrobiana e antibiofilme de frações de Salvia sclarea, assim como de diterpenos isolados da espécie, e verificaram a ação exclusiva contra bactérias Gram-positivas - S. aureus, S. epidermidis, Enterococcus faecalis, não apresentando efeito contra $P$. aeruginosa, $E$. coli nem contra o fungo Candida albicans. Em estudo realizado com oxilipinas e diterpenenos clerodanos isolados de Salvia adenofora, verificou-se resultado semelhante. Os compostos testados apresentaram efeito inibitório sobre $S$. aureus, S. epidermidis, Streptococcus agalactiae, E. faecalis e $E$. faecium, em concentrações variando de 1000 a $125 \mu \mathrm{g} / \mathrm{mL}$, no entanto, não inibiram o crescimento de E. coli, P. aeruginosa e C. albicans (BISIO et al., 2015).

Ainda, Schito et al. (2011), avaliando a atividade inibidora de biofilme de demetilfruticulina A e fruticulina A, duas quinonas diterpênicas isoladas de Salvia corrugata, contra cepas multirresistentes de $S$. aureus, S. epidermidis e E. faecalis, concluíram que as interações entre as moléculas testadas e as bactérias Gram-positivas são complexas, podendo ser específicas para cada espécie de patógeno, além de envolver inibição da síntese da matriz exopolissacarídica, ação quelante e alterações na superfície do microrganismo, como características de hidrofobicidade da célula. Enquanto, Bisio et al. (2015) atribuíram a inatividade dos compostos testados em relação aos patógenos Gram-negativos às diferenças estruturais existentes nas membranas destes microrganismos em relação às bactérias Gram-positivas. Bactérias Gram-negativas apresentam uma membrana externa altamente seletiva e hidrofóbica. 


\section{CONCLUSÕES}

Considerando o impacto para saúde humana e animal de microrganismos formadores de biofilme, como $S$. aureus e $P$. aeruginosa, assim como a dificuldade de combatê-los, os resultados obtidos no presente estudo com extratos de espécies de Eugenia nativas do sul do Brasil são extremamente promissores. As espécies analisadas apresentaram ação antimicrobiana contra células planctônicas, assim como inibiram a formação de biofilme tanto de $S$. aureus quanto de $P$. aeruginosa, sendo que a atividade pode estar relacionada à presença de flavonoides, saponinas, taninos e terpenos, os quais foram identificados como constituintes das espécies. Assim, além de apresentar pela primeira vez a avaliação da atividade antimicrobiana e antibiofilme das espécies estudadas, verifica-se a potencialidade das espécies nativas do gênero Eugenia, destacando-se aquelas originárias do bioma pampa $-E$. anomala, $E$. arenosa e $E$. pitanga, como fonte para o desenvolvimento de fármacos.

\section{AGRADECIMENTOS}

Este estudo recebeu apoio financeiro da Fundação de Amparo à Pesquisa do Estado do Rio Grande do Sul (FAPERGS) e do Conselho Nacional de Desenvolvimento Científico e Tecnológico (CNPq; PRONEX 10/0029-0).

\section{REFERÊNCIAS}

BARNECHE, S.; CERDEIRAS, M. P.; LUCARINI, R.; MARTINS, C. H.G.; OLIVARO, C.; VAZQUEZ, A. Anti-Staphylococcus Activity of Uruguayan Riverside Forest Plants. Pharmacognosy Journal, v. 3, n. 21, p. 69-71, 2011.

BISIO, A.; SCHITO, A. M.; EBRAHIMI, S. N.; HAMBURGER, M.; MELE, G.; PIATTI, G.; ROMUSSI, G.; DAL PIAZ, F.; DE TOMMASI, N. Antibacterial compounds from Salvia adenophora Fernald (Lamiaceae). Phytochemistry, v. 110, p. 120-132, 2015.

BLACKLEDGE, M. S.; WORTHINGTON, R. J.; MELANDER, C. Biologically inspired strategies for combating bacterial biofilms. Current Opinion in Pharmacology, v. 2013, p. 699-706, 2013.

BRIDIER, A.; SANCHEZ-VIZUETE, P.; GUILBAUD, M.; PIARD, J. C.; NAÏTALI, M. BRIANDET, R. Biofilm-associated persistence of food-borne pathogens. Food Microbiology, v. 45, p. 167-178, 2015.

BUSSMANN, R. W.; MALCA-GARCÍA, G.; GLENN, A.; SHARON, D.; CHAIT, G.; DÍAZ, D.; POURMAND, K.; JONAT, B.; SOMOGY, S.; GUARDADO, G.; AGUIRRE, C.; CHAN, R.; MEYER, K.; KUHLMAN, A.; TOWNESMITH, A.; EFFIO-CARBAJAL, J.; FRÍAS-FERNANDEZ, F.; BENITO, M. Minimum inhibitory concentrations of medicinal plants used in Northern Peru as antibacterial remedies. Journal of Ethnopharmacology, v. 132, p. 101-108, 2010. 
CHANDLER, R. F.; HOOPER, S. N. Friedelin and associated triterpenoids.

Phytochemistry, v. 18, p. 711-724, 1979.

CORREA, P. Dicionário das Plantas Úteis do Brasil e das Exóticas Cultivadas, vol. 5. Rio de Janeiro: Imprensa Nacional, 1984. p. 508-512.

FARIA JÚNIOR, Jair E. Q. O gênero Eugenia L. (Myrtaceae) nos estados de Goiás e Tocantis, Brasil. 2010. Dissertação (Mestrado) - Programa de Pós-Graduação em Botânica, Universidade de Brasília, Brasília, 2010.

FERREIRA, F. P. S; MORAIS, S. R.; BARA, M. T. F.; CONCEIÇÃO, E. C.; PAULA, J. R.; CARVALHO, T. C.; VAZ, B. G.; COSTA, H. B.; ROMÃO, W.; REZENDE, M. H. Eugenia calycina Cambess extracts and their fractions: Their antimicrobial activity and the identification of major polar compounds using electrospray ionization FT-ICR mass spectrometry. Journal of Pharmaceutical and Biomedical Analysis, v. 99, p. 89-96, 2014.

FLORA DIGITAL DO RIO GRANDE DO SUL E DE SANTA CATARINA: Eugenia pitanga (O.Berg) Nied. Disponível em: <http://www.ufrgs.br/fitoecologia/florars/index. php?pag=buscar_mini.php\&especie=2390>. Acesso em: 12 set. $2016 f$.

FRIGHETTO, N.; WELENDORF, R. M.; SILVA, A. M. P.; NAKAMURA, M. J.; SIANI, A. C. Aplicação de cromatografia centrífuga de contra-corrente na purificação de ácido ursólico das folhas de Eugenia brasiliensis Lam.. Revista Brasileira de Farmacognosia, v. 15, p. 338-343, 2005.

HARON, N. W.; MOORE, D. M.; HARBORNE, J. B. Distribution and taxonomic significance of flavonoids in the genus Eugenia (Myrtaceae). Biochemical Systematics and Ecology, v. 20, p. 266-268, 1992.

HOLETZ, F. B.; PESSINI, G. L.; SANCHES, N. R.; CORTEZ, D. A.; NAKAMURA, C. V., FILHO, B. P. Screening of some plants used in the Brazilian folk medicine for the treatment of infectious diseases. Memórias do Instituto Oswaldo Cruz, v. 97, n. 7, p. 10271031, 2002.

KUŹMA, L.; RÓŹALSKI, M.; WALENCKA, E.; RÓŹALSKA, B.; WYSOKIŃSKA, H. Antimicrobial activity of diterpenoids from hairy roots of Salvia sclarea L.: Salvipisone as a potential anti-biofilm agent active against antibiotic resistant Staphylococci. Phytomedicine, v. 14, p. 31-35, 2007.

LEE, M. H.; NISHIMOTO, S.; YANG, L. L.; YEN, K. Y.; HATANO, T.; YOSHIDA, T.; OKUDA, T. Two macrocyclic hydrolysable tannin dimers from Eugenia uniflora.

Phytochemistry, v. 44, p. 1343-1349, 1997.

LUNARDI, I.; PEIXOTO, J. L. B.; SILVA, C. C.; SHUQUEL, I. T. A.; BASSO, E. A.; VIDOTTI, G. J. Triterpenic acids from Eugenia moraviana. Journal of Brazilian Chemistry Society, v. 12, p. 180-183, 2001.

MAGINA, M. D. A.; DALMARCO, E. M.; DALMARCO, J. B.; COLLA, G.; PIZZOLATTI, M. G.; BRIGHENTE, I. M. C. Bioactive triterpenes and phenolics of leaves of Eugenia brasiliensis. Química Nova, v. 35, n. 6, p. 1184-1188, 2012. 
MAHMOUD, I. I.; MARZOUK, M. S. A.; MOHARRAM, F. A.; EL-GINDI, M. R.; HASSAN, A. M. K. Acylated flavonol glycosides from Eugenia jambolana leaves.

Phytochemistry, v. 58, p. 1239-1244, 2001.

NIKAIDO, H. Preventing drug access to targets: cell surface permeability barriers and active efflux in bacteria. Cell \& Developmental Biology, v. 12, p. 215-223, 2001.

NONAKA, G. I.; ISHIMARU, K.; WATANABE, M.; NISHIOKA, I.; YAMAUCHI, T.; WAN, A. S. C. Tannins and related compounds. LI. Elucidation of the stereochemistry of the triphenoyl moiety in castalagin and vescalagin, and isolation of 1-O-galloyl castalagin from Eugenia grandis. Chemical and Pharmaceutical Bulletin, v. 35, p. 217-220, 1987.

OGUNWANDE, I. A.; OLAWORE, N. O.; EKUNDAYO, O.; WALKER, T. M.; SCHMIDT, J. M.; SETZER, W. N. Studies on the essential oils composition, antibacterial and cytotoxicity of Eugenia uniflora L. The International Journal of Aromatherapy, v.15, n.3, p.147-152, 2005.

OLIVEIRA, R. N.; DIAS, I. J. M.; CÂMARA, C. A. G. Estudo comparativo do óleo essencial de Eugenia punicifolia (HBK) DC. de diferentes localidades de Pernambuco. Revista Brasileira de Farmacognosia, v. 15, n. 1, p. 39-43, 2005.

PETON, V.; LE LOIR, Y. Staphylococcus aureus in veterinary medicine. Infection, Genetics and Evolution, v. 21, p. 602-615, 2014.

SCHITO, A. M.; PIATTI, G.; STAUDER, M.; BISIO, A.; GIACOMELLI, E.;

ROMUSSI, G.; PRUZZO, C. Effects of demethylfruticuline A and fruticuline A from Salvia corrugata Vahl. on biofilm production in vitro by multiresistant strains of Staphylococcus aureus, Staphylococcus epidermidis and Enterococcus faecalis. International Journal of Antimicrobial Agents, v. 37, p. 129-134, 2011.

SOBRAL, M.; JARENKOW, J. A.; BRACK, P.; IRGANG, B.; LAROCCA, J.; RODRIGUES, R. S. Flora Arbórea e Arborescente do Rio Grande do Sul, Brasil. 2 ed. São Carlos: Rima, 2013. p. 130-131.

SOUSA, R. M. F.; DE MORAIS, S. A. L.; VIEIRA, R. B. K.; NAPOLITANO, D. R.; GUZMAN, V. B.; MORAES, T. S.; CUNHA, L. C. S.; MARTINS, C. H. G.; CHANG, R.; DE AQUINO, F. J. T.; DO NASCIMENTO, E. A.; DE OLIVEIRA, A. Chemical composition, cytotoxic, and antibacterial activity of the essential oil from Eugenia calycina Cambess. leaves against oral bacteria. Industrial Crops and Products, v. 65, p. 71-78, 2015.

SOUZA, G. C.; HAAS, A. P. S.; VON POSER, G. L.; SCHAPOVAL, E. E.; ELISABETSKY, E. 2004. Ethnopharmacological studies of antimicrobial remedies in the south of Brazil. Journal of Ethnopharmacology, v. 90, n. 1, p. 135-143, 2004.

SOUZA, V. C.; LORENZI, H. Botânica sistemática: guia ilustrado para identificação das famílias de fanerógamas nativas e exóticas no Brasil, baseado em APG III. 3. ed. Nova Odessa: Instituto Plantarum, 2012. p. 428-429.

SREY, S.; JAHID, I. K.; HA, S. Biofilm formation in food industries: A food safety concern. Food Control, v. 31, p. 572-585, 2013. 
TARASZKIEWICZ, A.; FILA, G.; GRINHOLC, M.; NAKONIECZNA, J. Innovative strategies to overcome biofilm resistance. BioMed Research International, v. 2013. 13 p., 2013. Article ID 150653. Disponível em <http://dx.doi.org/10.1155/2013/150653>. Acesso em: 25 ago. 2016.

THEURETZBACHER, U. Global antibacterial resistance: The never-ending story. Journal of Global Antimicrobial Resistance, v. 1, p. 63-69, 2013.

TRENTIN, D. S.; GIORDANI, R. B.; ZIMMER, K. R.; SILVA, A. G.; SILVA, M. V.; CORREIA, M. T. S.; BAUMVOL, I. J. R.; MACEDO, A. J. Potential of medicinal plants from the Brazilian semi-arid region (Caatinga) against Staphylococcus epidermidis planktonic and biofilm lifestyles. Journal of Ethnopharmacology, v. 137, p. 327-335, 2011.

TRENTIN, D. S; GIORDANI, R. B.; MACEDO, A. J. Biofilmes bacterianos patogênicos: aspectos gerais, importância clínica e estratégias de combate. Revista Liberato, v. 14, p. 113238, 2013.

VILLA, F; CAPPITELLI, F. Plant-derived bioactive compounds at sub-lethal concentrations: towards smart biocide-free antibiofilm strategies. Phytochemistry Reviews, v. 12, p. 245-254, 2013.

WAGNER, H.; BLADT. S. Plant drug analysis. 2 ed., New York: Springer Verlag, 1996. 384 pp. 